Check for updates

Cite this: RSC Adv., 2017, 7, 23779

Received 14th February 2017 Accepted 17th April 2017

DOI: $10.1039 / c 7 r a 01859 b$

rsc.li/rsc-advances

\section{Efficient small molecule photovoltaic donor based on 2,3-diphenyl-substituted quinoxaline core for solution-processed organic solar cells $\uparrow$}

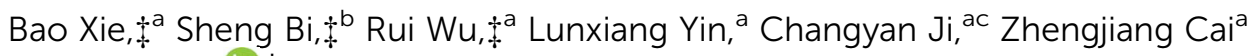 \\ and Yanqin Li iD *a
}

A novel $D-\pi-A-\pi-D$-type organic small molecule (OSM) named $(T P A C N)_{2} Q x$ was designed and synthesized for solution-processible organic solar cells (OSCs), which contained 2,3-diphenylsubstituted quinoxaline $(\mathrm{Qx})$ as the central acceptor (A) unit, triphenylamine (TPA) as terminal electrondonor (D) moieties, and acrylonitrile as the $\pi$-linkage segment. With an effective electron-withdrawing property and relatively stable quinoid geometry of $\mathrm{Qx}$, (TPACN $)_{2} \mathrm{Qx}$ exhibits a narrow band-gap of $1.88 \mathrm{eV}$ and strong and broad absorption at 300-700 nm. As a consequence, an excellent power conversion efficiency (PCE) of $6.25 \%$ was achieved based on the (TPACN) ${ }_{2} \mathrm{Qx}: \mathrm{PC}_{61} \mathrm{BM}$ blend using a simple spin-coating process in a solution, which is the highest efficiency achieved to date for Qx-core based solution-processed OSM photovoltaic (PV) devices. The impressive result demonstrates that OSMS employing quinoxaline derivative as an electrophilic unit can compete with their polymer counterparts.

\section{Introduction}

OSCs have emerged as a competitive alternative to inorganic solar cells for their prominent advantages of light weight, low cost and flexibility in large-scale fabrication. ${ }^{1}$ Over the past two decades, solution-processed bulk heterojunction (BHJ) photovoltaic (PV) devices based on a blend of electron donors and acceptors have attracted much attention and extensive investigation due to their higher internal quantum efficiency and the easier fabrication technology. ${ }^{2}$ Nowadays, most research efforts have been focused on donor materials because fullerene derivatives, such as $[6,6]$-phenyl- $\mathrm{C}_{61}$-butyric acid methyl ester $\left(\mathrm{PC}_{61} \mathrm{BM}\right)$ and [6,6]-phenyl- $\mathrm{C}_{71}$-butyric acid methyl ester $\left(\mathrm{PC}_{71} \mathrm{BM}\right)$, have proven to be ideal acceptor materials and have already been commercialized. ${ }^{3}$ Among the OSC donor materials, OSM materials have shown numerous promising advantages over conjugated polymers in terms of well-defined structure, easier purification, better batch-to-batch reproducibility and high charge carrier mobility. ${ }^{4}$ In particular, an

${ }^{a}$ School of Chemistry, Dalian University of Technology, Linggong Road 2, Dalian, P. R. China. E-mail: liyanqin@dlut.edu.cn; Fax: +86-411-84986040; Tel: +86-41184986040

${ }^{b}$ School of Mechanical Engineering, Dalian University of Technology, Linggong Road 2, Dalian, P. R. China

${ }^{\prime}$ Hunan Provincial Key Laboratory of Fine Ceramics and Powder Materials, Hunan University of Humanities, Science and Technology, Lou'di, Hunan 417000, P. R. China $\dagger$ Electronic supplementary information (ESI) available: Synthetic procedures, NMR spectra, computational electronic transitions of the synthesized compounds and AFM images of blend films. See DOI: 10.1039/c7ra01859b

¥ The authors have equal contribution to the manuscript. encouraging PCE of $11.30 \%$ has been achieved based on OSM donor materials, ${ }^{5}$ which is comparable to the PV performance of the best polymers. ${ }^{6}$ However, the overall performance of OSMs, to date, is still behind those of their polymer counterparts. Therefore, BHJ OSCs based on OSMs still require intensive investigation for the design of materials.

To design ideal OSM donor materials, the following issues should be considered: ${ }^{7}$ (I) possessing broad and strong absorption via reducing the band-gap $\left(E_{\mathrm{g}}\right)$ of molecules, which results in an increased short-circuit current density $\left(J_{\mathrm{sc}}\right)$; (II) lowering the highest occupied molecular orbit (HOMO) of materials, which correlates with the improved open-circuit voltage $\left(V_{\mathrm{oc}}\right)$; (III) possessing better solubility, miscibility and film-forming characteristics to improve the morphology of the active layer and increase the fill factor (FF) of the PV device. To address these issues, developing new D-A conjugated molecules has become an effective strategy as the $E_{\mathrm{g}}$ and energy levels of D-A-type OSMs can be effectively tuned through chemical structure modifications. ${ }^{8}$ In our previous study, we found that OSMs with alternating D-A conjugated configuration could possess both lower HOMO level and narrow band-gap by tuning their building blocks. ${ }^{9}$ We have reported a D- $\pi-A-\pi-D$-type OSM donor material, BDCTBT, ${ }^{\mathbf{1 0}}$ in which benzothiadiazole (BT) as the A unit and TPA as the D unit were connected by a $\pi$ bridge containing an acrylonitrile segment, and the chemical structure of BDCTBT is shown in Fig. 1. In practical photovoltaic testing, the devices based on BDCTBT as donor and $\mathrm{PC}_{61} \mathrm{BM}$ as acceptor exhibited a PCE of $3.85 \%,{ }^{10}$ and after subsequent device optimization, a relatively high PCE of $4.84 \%$ was obtained. ${ }^{\boldsymbol{b}}$ Our research demonstrates that $\mathrm{D}-\mathrm{A}-\mathrm{D}$-type molecules 


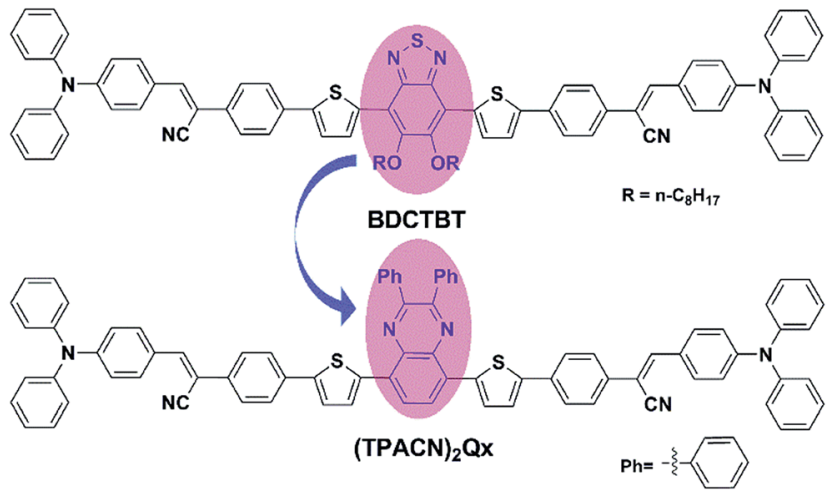

Fig. 1 Chemical structures of (TPACN) ${ }_{2} \mathrm{Qx}$ and BDCTBT.

with a $\pi$-bridge containing an acrylonitrile segment are a successful configuration for OSM donor material. To date, we have found that the PCEs of solution-processed BHJ devices based on D-A-D-type OSM with BT as the electrophilic core have never exceeded $5 \% .{ }^{8 c, 9 b, 11}$ Based on above design concepts, we synthesized a new D-A-D-type OSM named (TPACN) ${ }_{2} \mathbf{Q} \mathbf{x}$ as shown in Fig. 1, in which the central A unit of BDCTBT was replaced by a strong electron-withdrawing unit, which was 2,3diphenyl-substituted quinoxaline (Qx).

Quinoxaline, as one significant class of high performance pigments, is widely considered as a promising building block for OSCs due to the strong electron-withdrawing property of two imine nitrogens and relatively stable quinoid geometry. ${ }^{12}$ Quinoxaline derivatives can be easily structurally modified, and their electronic properties can be changed with various substituents. Among a wide variety of quinoxaline derivatives, Qx has shown to be an easily synthesized excellent electronwithdrawing unit for the synthesis of narrow band gap conjugated polymers used in high efficiency polymer solar cells (PSCs). ${ }^{13}$ Thus far, PSCs based on Qx have achieved promising PCEs over $8 \%$ with careful device optimization. ${ }^{14}$ In addition, important progress has also been made on Qx-based dye sensitized solar cells (DSSCs) with a PCE near $10 \%{ }^{15}$ Although Qx shows outstanding PV performance in PSCs and DSSCs, it seems to be hysteretic in OSM solar cells. ${ }^{16}$ Consequently, we believe that Qx-based OSMs possess tremendous development potential for BHJ-OSCs.

Accordingly, (TPACN) $)_{2} \mathbf{Q x}$ was designed and synthesized successfully, and its photoelectric properties were fully investigated. Remarkably, an excellent PCE of $6.25 \%$ has been achieved for $\mathrm{BHJ}$ devices based on (TPACN) ${ }_{2} \mathbf{Q x}$ as the donor and $\mathbf{P C}_{61} \mathrm{BM}$ as the acceptor, which is the highest efficiency reported to date for solution processed Qx-based OSM BHJ-OSCs. This study clearly indicates that Qx-based OSMs possess great potential in obtaining high performance for solution-processed PV devices.

\section{Experimental}

\section{Reagents and materials}

All reagents were purchased commercially and used without further purification unless specified. All reactions were carried out with the standard Schlenk technique unless otherwise indicated. Toluene and tetrahydrofuran (THF) were pretreated over sodium/benzophenone under nitrogen atmosphere before reaction.

\section{Photovoltaic device fabrication}

The BHJ device was fabricated via solution-processable spincoating process with a typical architecture of ITO/PEDOT:PSS/ donor: $\mathrm{PC}_{61} \mathrm{BM} / \mathrm{Al}$. The ITO-glass substrates were cleaned in an ultrasonic bath in deionized water, methanol, acetone, toluene and isopropanol for $5 \mathrm{~min}$, successively. After being dried with high pressure nitrogen gas-flow, a thin layer of poly(3,4ethylenedioxythiophene):poly(styrene sulfonate) (PEDOT : PSS) was spin-coated onto the pretreated substrate at $4000 \mathrm{rpm} \mathrm{s}^{-1}$ for $60 \mathrm{~s}$. After being baked at $120{ }^{\circ} \mathrm{C}$ for $15 \mathrm{~min}$, all prepared substrates were transferred into the nitrogen-filled glovebox. Then, the blended solution of (TPACN) $)_{2} \mathbf{Q x}$ and $\mathrm{PC}_{61} \mathrm{BM}$ in chloroform with various weight ratios was spin-coated on the top of the prepared substrate at $1500 \mathrm{rpm} \mathrm{s}^{-1}$ for $60 \mathrm{~s}$. Finally, an aluminium layer as the electrode was deposited on top of the active layer by thermal evaporation under vacuum $\left(c a .10^{-4} \mathrm{~Pa}\right)$, yielding six individual cells with $5 \mathrm{~mm}^{2}$ effective area for each. The hole-only devices using high work-function metal gold $(\mathrm{Au})$ as the electrode for hole mobility measurement were fabricated with a structure of ITO/PEDOT:PSS/donor:PC ${ }_{61} \mathrm{BM} / \mathrm{Au}$.

\section{Measurements and characterization}

${ }^{1} \mathrm{H}$-NMR and ${ }^{13} \mathrm{C}$-NMR spectra were recorded by Bruker AVANCE II $400 \mathrm{MHz}$ spectrometer with $\mathrm{CDCl}_{3}$ as solvent and tetramethylsilane (TMS) as internal standard substance. High resolution mass spectra (HRMS) were recorded with a MALDI Micro MX spectrometer. The UV-Vis absorption spectra of the material in chloroform solution and in the film state were taken on an Agilent Cary 5000 spectrophotometer. Cyclic voltammetry (CV) experiments were conducted using a CHI610D electrochemical workstation from $\mathrm{CH}$ Instruments, Inc., and it was performed in $0.1 \mathrm{M}$ anhydrous $\mathrm{Bu}_{4} \mathrm{NBF}_{4} / \mathrm{CH}_{2} \mathrm{Cl}_{2}$ solution at a scan rate of $100 \mathrm{mV} \mathrm{s}^{-1}$ under nitrogen atmosphere, using the glass-carbon electrode, $\mathrm{Ag} / \mathrm{Ag}^{+}$electrode $\left(\mathrm{Ag}\right.$ in $0.1 \mathrm{M} \mathrm{AgNO}_{3}$ solution of MeCN) and platinum wire electrode as the working electrode, reference electrode and counter electrode, respectively. In addition, the ferrocene-ferrocenium $\left(\mathrm{Fc} / \mathrm{Fc}^{+}\right)$couple was selected as the internal standard. Electrochemical band gaps $\left(E_{\mathrm{g}}^{\mathrm{CV}}\right)$ and the pertinent energy levels $\left(\mathrm{HOMO}^{\mathrm{CV}}\right.$ and $\mathrm{LUMO}^{\mathrm{CV}}$ ) could be achieved according to the following empirical equations: ${ }^{17} \mathrm{HOMO}^{\mathrm{CV}} / \mathrm{LUMO}^{\mathrm{CV}}=-\left[E_{\text {ox/red }}-E_{1 / 2}^{\mathrm{ferrocene}}+\right.$ $4.8] \mathrm{eV}$ and $E_{\mathrm{g}}^{\mathrm{CV}}=\mathrm{LUMO}^{\mathrm{CV}}-\mathrm{HOMO}^{\mathrm{CV}}$, where $E_{\text {ox }}$ was the measured onset oxidation potential and $E_{\text {red }}$ was the measured onset reduction potential relative to $\mathrm{Ag} / \mathrm{Ag}^{+}$, and $E_{1 / 2}^{\text {ferrocene }}=$ $0.05 \mathrm{eV}$ versus $\mathrm{Ag} / \mathrm{Ag}^{+}$. Thermogravimetric analysis (TGA) was carried out on a TA Instruments Q50 thermogravimetric analyzer at a heating rate of $10{ }^{\circ} \mathrm{C} \mathrm{min}^{-1}$ under nitrogen atmosphere. Differential scanning calorimetry (DSC) was performed under nitrogen atmosphere at a heating/cooling rate of $10{ }^{\circ} \mathrm{C}$ min $^{-1}$ with a TA Instruments Q20 differential scanning calorimeter. Atomic force microscopy (AFM) measurement was 
conducted with a DI Nanoscope Dimension 3100 atomic force microscope. The current density-voltage $(J-V)$ characteristics of PV devices were measured with a computer-controlled Keithley 2400 Source Measure Unit under simulated AM 1.5 G illumination with an intensity of $100 \mathrm{~mW} \mathrm{~cm}^{-2}$, calibrated with a standard silicon solar cell. The incident-photons-to-current efficiency (IPCE) measurement was recorded on a SM-25 photoelectric conversion analyzer. The hole-mobility $\left(\mu_{\mathrm{h}}\right)$ measurement of the material was performed with the Keithley 2400 Source Measure Unit system in dark. The $\mu_{\mathrm{h}}$ data can be received by fitting the $J-V$ curves in a double logarithmic scale with a space-charge-limited current (SCLC) model according to the Mott-Gurney law: ${ }^{18} J=(9 / 8) \varepsilon_{0} \varepsilon_{\mathrm{r}} \mu_{\mathrm{h}}\left(V^{2} / L^{3}\right)$, where $J$ is current density, $\varepsilon_{0}$ is the permittivity of free space, $\varepsilon_{\mathrm{r}}$ is the relative permittivity and assumed as approximately $3.0, \mu_{\mathrm{h}}$ is the hole mobility value, $V$ is the effective voltage, and $L$ is the thickness of the active layer.

\section{Synthetic procedures}

The synthetic process of (TPACN) ${ }_{2} \mathbf{Q x}$ is described in Scheme 1.

The quinoxaline-based acceptor (compound A) was synthesized in six steps starting from commercially available 1,2benzenediamine following the procedures reported in literature. ${ }^{\mathbf{1 0 , 1 2 b , 1 9}}$ Starting from the commercialized triphenylamine as original material, a solution of $\mathrm{POCl}_{3}$ and $\mathrm{N}, \mathrm{N}$-dimethylformamide (DMF) was dropped carefully via Vilsmeier reaction to obtain compound $\mathbf{1}$. Knoevenagel condensation reaction of 4-bromophenyl acetonitrile and 4-(diphenylamino) benzaldehyde was carried out using $\mathrm{NaOH}$ as a base in $\mathrm{EtOH}$, resulting in compound 2 in a yield of 91\%. The donor unit (compound D) was synthesized by Miyauraborylation of compound 2 and bis(pinacolato)diborane in a yield of $81 \%$. Finally, (TPACN) $)_{2} \mathbf{Q x}$ was prepared by $\mathrm{Pd}\left(\mathrm{PPh}_{3}\right)_{4}$-assisted Suzuki coupling reaction of compound $\mathbf{D}$ and compound $\mathbf{A}$ in a yield of $90 \%$. Detailed synthetic procedures and characterization are given in ESI. $\dagger$ Mp: $290-293{ }^{\circ} \mathrm{C} .{ }^{1} \mathrm{H}-\mathrm{NMR}$ (400 $\mathrm{MHz}, \mathrm{CDCl}_{3}$ ):

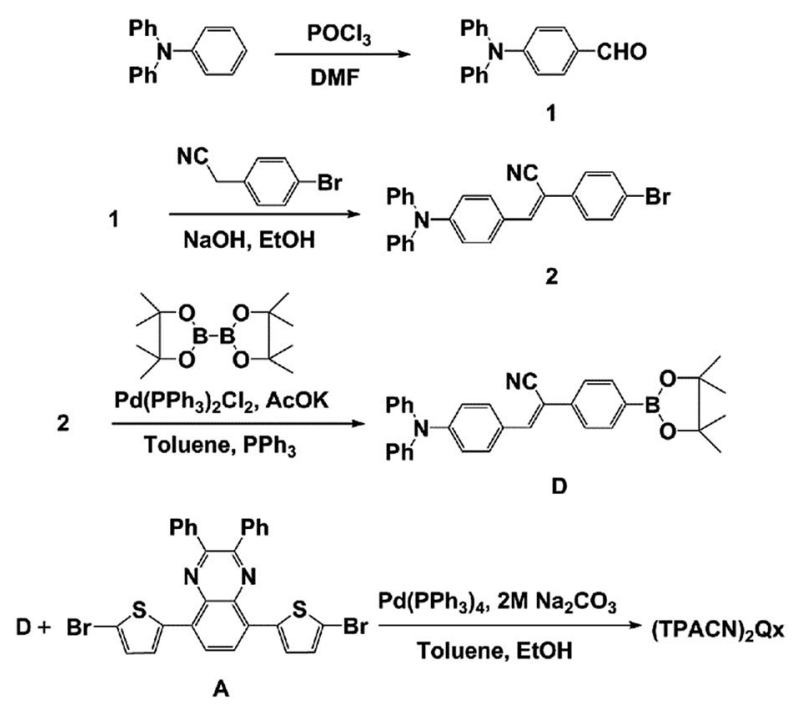

Scheme 1 Synthetic routes of $(\mathrm{TPACN})_{2} \mathrm{Qx}$. $\delta 8.10(\mathrm{~s}, 2 \mathrm{H}), 7.78(\mathrm{~d}, J=8.0 \mathrm{~Hz}, 10 \mathrm{H}), 7.66(\mathrm{~m}, 8 \mathrm{H}), 7.48-7.39$ $(\mathrm{m}, 10 \mathrm{H}), 7.32(\mathrm{t}, J=8.0 \mathrm{~Hz}, 8 \mathrm{H}), 7.17-7.11(\mathrm{~m}, 12 \mathrm{H}), 7.07(\mathrm{~d}, J=$ $8.0 \mathrm{~Hz}, 4 \mathrm{H}) .{ }^{13} \mathrm{C}-\mathrm{NMR}\left(100 \mathrm{MHz}, \mathrm{CDCl}_{3}\right): \delta 151.67,149.99$, 146.66, 146.63, 146.06, 140.90, 138.60, 137.14, 134.89, 133.84, $130.95,130.73,130.61,129.60,129.25,128.27,127.48,126.47$, 126.37, 126.08, 125.89, 125.77, 124.43, 123.33, 120.86, 118.69, 107.19. MALDI-TOF HRMS: $1187.3934\left[\mathrm{M}^{+}\right]$(calcd for $\mathrm{C}_{82} \mathrm{H}_{55} \mathrm{~N}_{6} \mathrm{~S}_{2}$ : 1187.3930).

\section{Results and discussion}

\section{Material characterization and thermal properties}

The chemical structure of the newly synthesized compound (TPACN) ${ }_{2}$ Qx was confirmed by ${ }^{1} \mathrm{H}-\mathrm{NMR},{ }^{13} \mathrm{C}$-NMR spectroscopy and MALDI-TOF HRMS, as shown in the Experimental section. These results are consistent with the proposed structure and molecular weight. Furthermore, (TPACN) ${ }_{2} \mathbf{Q x}$ possesses excellent solubility in common organic solvents such as chloroform, dichlorobenzene, and toluene, which meets the requirement for solution-processable PV device fabrication.

The thermal stability properties of the material were investigated first by means of thermogravimetric analysis (TGA). The 5\% weight loss temperature $\left(T_{\mathrm{d}}\right)$ of (TPACN) $)_{2} \mathbf{Q x}$ was determined from TGA curves, as shown in Fig. 2(a). It exhibits particularly high thermal stability with a $T_{\mathrm{d}}$ greater than $494{ }^{\circ} \mathrm{C}$, which is $151{ }^{\circ} \mathrm{C}$ higher than $T_{\mathrm{d}}$ of the reference compound BDCTBT as plotted in the inset of Fig. 2(a). In addition, the thermal properties of (TPACN) ${ }_{2}$ Qx were investigated by differential scanning calorimetry (DSC) analysis. Fig. 2(b) shows the DSC curves of (TPACN) $)_{2} \mathbf{Q x}$ at a heating/cooling rate of $10{ }^{\circ} \mathrm{C} \mathrm{min}^{-1}$ under a nitrogen flow. When (TPACN) ${ }_{2} \mathbf{Q x}$ was heated, the endothermic peak due to the melting temperature was observed at $319{ }^{\circ} \mathrm{C}$. Cooling process exhibited an opposite exothermic peak due to crystallization at $c a$. $227{ }^{\circ} \mathrm{C}$, and the corresponding enthalpy was $78.8 \mathrm{~kJ} \mathrm{~mol}^{-1}$. The larger crystallization enthalpy indicates that it has a tendency to crystallize to keep its stability. In should be noted that the crystallization of the materials in the active layer is beneficial to charge separation and transport in PV applications. ${ }^{20}$

\section{Theoretical calculations}

The computational analysis can be used to screen a variety of OSMs and highlight some promising chemical structures to

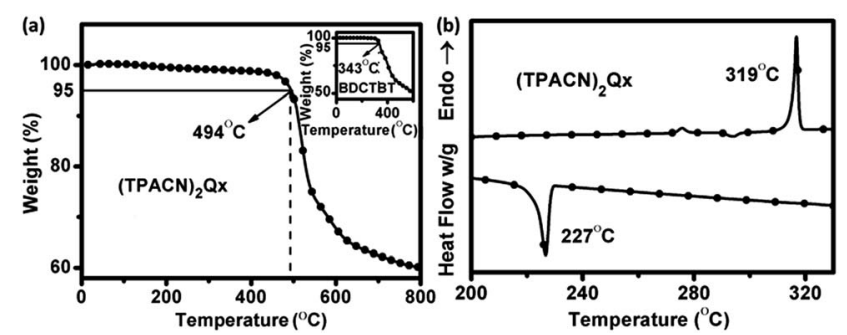

Fig. 2 (a) TGA curve of (TPACN) $)_{2} \mathrm{Qx}$ at a heating rate of $10^{\circ} \mathrm{C} \mathrm{min}^{-1}$ under a nitrogen atmosphere. Inset: TGA analysis of BDCTBT as a contrast. (b) DSC curves of (TPACN) ${ }_{2} \mathrm{Qx}$ at a heating/cooling rate of $10{ }^{\circ} \mathrm{C} \mathrm{min}^{-1}$ under a nitrogen flow. 
pursue synthetically, which is also desirable for investigation of the theoretical optical and electronic properties of new materials. ${ }^{21}$ In this study, we preliminarily predict the molecular geometry and investigate the theoretical optical and electronic properties of (TPACN) ${ }_{2} \mathbf{Q x}$ with density functional theory (DFT) and time dependent-density functional theory (TD-DFT) using Gaussian 09 software with the Becke's three-parameter gradient-corrected functional (B3LYP) with a polarized 6$31 \mathrm{G}(\mathrm{d})$ basis set. $^{22}$ The summary of the computational results is represented in Fig. 3, with the calculated data of electronic transitions included in the ESI $\dagger$. The optimized geometry of (TPACN) $)_{2}$ Qx and calculated dihedral angles are shown in Fig. 3(a). According to the optimized molecular geometry, the torsion angles between the Qx and thiophene units are $c a .14^{\circ}$, resulting in the molecular backbone being slightly distorted from planarity, and this distortion is a result of steric demand of the molecular structure. As expected, the torsion angles between the acrylonitrile linker and terminal TPA unit are only ca. $4^{\circ}$, which depict a considerably coplanar structure. As we know, the coplanar properties of the molecular backbone could probably have a pronounced influence on the optical and
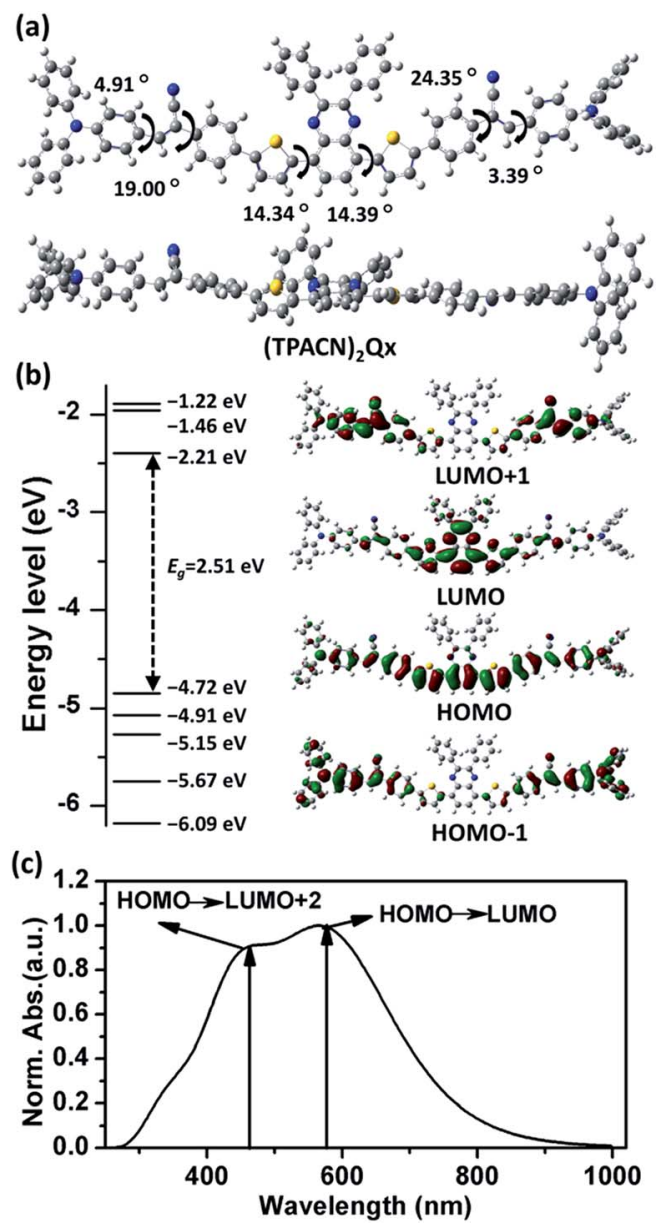

Fig. 3 Theoretical computational analysis for (TPACN) ${ }_{2} Q x$ (a) optimized ground-state geometry and dihedral angles; (b) calculated energy levels and molecular orbital depictions; and (c) predicted absorption spectrum and electronic transitions. electronic properties of materials. Herein, a theoretically effective intramolecular charge transfer (ICT) process between terminal TPA and central Qx via the $\pi$-linker could be predicted.

The computational energy levels and molecular orbital depictions are plotted in Fig. 3(b), with detailed electronic transition data included in Table S1 of ESI†. The electronic densities of the HOMO are highly distributed on the entire molecular backbone without a significantly biased distribution, whereas those of lowest unoccupied molecular orbital (LUMO) are predominantly localized at the central electrophilic core (Qx), revealing an apparent ICT process from the electrondonating segment to the electron-withdrawing unit. Furthermore, the electronic densities of HOMO-1 are predominantly located on their terminal segments with a greater proportion. This feature reveals that the terminal TPA group could probably play an important role in stabilizing the separated hole and thus improve the hole transporting capacity. ${ }^{23}$ The calculated energy levels of the HOMO ${ }^{\mathrm{DFT}}$ and $\mathrm{LUMO}^{\mathrm{DFT}}$ are $-4.72 \mathrm{eV}$ and $-2.21 \mathrm{eV}$, respectively. Despite the error between theory and experimental results, the computational analysis has proven to be desirable for early design of new materials. ${ }^{24}$

The theoretical optical absorption spectrum of (TPACN) $)_{2} \mathbf{Q x}$ with the related electronic transitions is shown in Fig. 3(c). Accordingly, two primary absorption bands were observed. The long wavelength absorption band resulted from the first singlet excited state, which could be attributed to the electron transition from HOMO to LUMO. The short one primarily resulted from the sixth singlet excited state, which is a result of the electron transition from HOMO to LUMO+2. Despite the discrepancy between simulation and experiment caused by solvent effects and intermolecular interactions and so on, the computational results could provide important reference for the experimental data.

\section{Optical properties}

The optical properties of (TPACN) ${ }_{2} \mathbf{Q x}$ were studied using UV-Vis absorption measurement. The absorption profiles in chloroform solution and in the film state are shown in Fig. 4 with the corresponding optical data summarized in Table 1. This compound exhibits two primary absorption peaks in a broad absorption range covering 300-600 $\mathrm{nm}$ in solution and 300$700 \mathrm{~nm}$ in film. Moreover, the quantitative measurement of absorption in solution (inset of Fig. 4) shows that this compound possesses strong absorption capacity with a high molar extinction coefficient $(\varepsilon)$ of $1.08 \times 10^{5}$ and $9.08 \times 10^{4} \mathrm{M}^{-1}$ $\mathrm{cm}^{-1}$ at 433 and $482 \mathrm{~nm}$, respectively. In comparison with the ICT-induced maximum absorption peak in the long wavelength $\left(\lambda^{\text {sol }}\right)$ of (TPACN) $)_{2} \mathbf{Q x}$, the spectrum in the film state is greatly broadened, and the ICT-induced absorption peak ( $\left.\lambda^{\text {film }}\right)$ is redshifted $25 \mathrm{~nm}$, indicating a strong intermolecular $\pi-\pi$ interaction in the solid state. Accordingly, the optical band gap $\left(E_{\mathrm{g}}^{\mathrm{opt}}\right)$ of (TPACN $)_{2} \mathbf{Q x}$ estimated with its absorption onset is $1.94 \mathrm{eV}$, which is smaller than $E_{\mathrm{g}}^{\mathrm{opt}}$ of the reference compound BDCTBT as listed in Table 1 . This result is in accordance with its experimental band gap via the electrochemical method. Therefore, (TPACN) $)_{2} \mathbf{Q x}$ obtained a smaller value of 


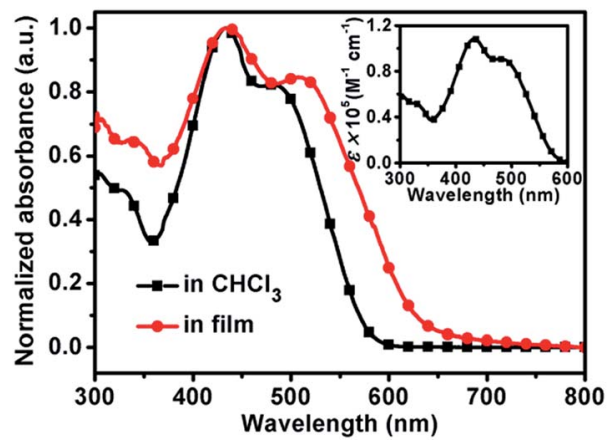

Fig. 4 Normalized UV-Vis absorption spectra of $(T P A C N)_{2} Q x$ in chloroform solution and in the film state. Inset: quantitative measurement of absorption spectra in chloroform solution at a concentration of $1.0 \times 10^{-5} \mathrm{~mol} \mathrm{~L}^{-1}$.

$E_{\mathrm{g}}^{\text {opt }}$ compared to that of BDCTBT, which could probably contribute to an efficient short-circuit current.

\section{Electrochemical properties}

To investigate the electrochemical property of (TPACN) $)_{2} \mathbf{Q x}$, cyclic voltammetry (CV) measurement was carried out in $0.1 \mathrm{M}$ $\mathrm{Bu}_{4} \mathrm{NBF}_{4} / \mathrm{CH}_{2} \mathrm{Cl}_{2}$ solution under the protection of nitrogen (the experimental details are described in the Experimental section). The cyclic voltammogram of (TPACN) $)_{2} \mathbf{Q x}$ and corresponding electrochemical energy-level diagram are depicted in Fig. 5, with the pertinent data summarized in Table 1 . The onset oxidation potential $\left(E_{\mathrm{Ox}}\right)$ at $0.4 \mathrm{~V}$ is clearly observed in the anode potential region as a result of the oxidation of the TPA unit. On the other hand, the onset reduction potentials $\left(E_{\mathrm{red}}\right)$ at $-1.48 \mathrm{~V}$ are easily obtained in the cathodic potential region due to the reduction of Qx as the electron-withdrawing core. The electrochemical energy levels $\left(\mathrm{HOMO}^{\mathrm{CV}}\right.$ and $\mathrm{LUMO}^{\mathrm{CV}}$ ) and band gap $\left(E_{\mathrm{g}}^{\mathrm{CV}}\right)$ could be calculated from $E_{\text {ox }}$ and $E_{\text {red }}$ (the calculation methods are recorded in the Experimental section). Accordingly, the $\mathrm{HOMO}^{\mathrm{CV}}$ of (TPACN) ${ }_{2} \mathrm{Qx}$ is $-5.15 \mathrm{eV}$, and the $\mathrm{LUMO}^{\mathrm{CV}}$ is $-3.27 \mathrm{eV}$, resulting in a narrow $E_{\mathrm{g}}^{\mathrm{CV}}$ of $1.88 \mathrm{eV}$. Therefore, (TPACN) $)_{2}$ Qx obtained a smaller value of $E_{\mathrm{g}}^{\mathrm{CV}}$ relative to that of BDCTBT, which could be rationally ascribed to the strong electron-withdrawing effect of Qx with electrophilic characteristics. This result is in good agreement with the spectral data. Herein, the improvement of $J_{\mathrm{sc}}$ of the PV device will be expected as a result of the decreased energy gap of (TPACN) ${ }_{2} \mathbf{Q x}$ relative to that of BDCTBT. The electrochemical energy level of (TPACN) $)_{2} \mathrm{Qx}$ together with $\mathrm{PC}_{61} \mathrm{BM}$ was plotted in Fig. $5(\mathrm{~b})$. These results clearly indicate that this compound in principle can behave as a donor in the $\mathrm{BHJ} \mathrm{PV}$ device with $\mathrm{PC}_{61} \mathrm{BM}$ as the acceptor material.
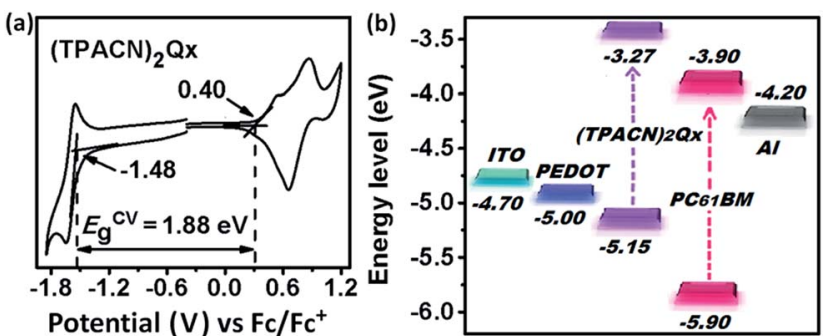

Fig. 5 (a) Cyclic voltammogram of (TPACN) $)_{2} \mathrm{Qx}$ in $0.1 \mathrm{M} \mathrm{Bu}_{4} \mathrm{NBF}_{4} /$ $\mathrm{CH}_{2} \mathrm{Cl}_{2}$ solution at a scan rate of $100 \mathrm{mV} \mathrm{s}^{-1}$; (b) energy-level diagram of the components for (TPACN) ${ }_{2} \mathrm{Qx}$-based photovoltaic device.
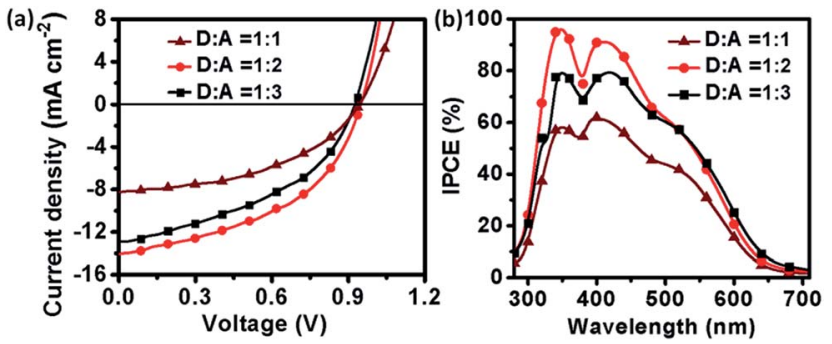

Fig. 6 (a) $J-V$ curves of the PV devices based on a blend of (TPACN) ${ }_{2} \mathrm{Qx}$ and $\mathrm{PC}_{61} \mathrm{BM}$ with varied $\mathrm{D} / \mathrm{A}$ weight ratios $(1: 1,1: 2$ and 1 : 3) under an illumination of AM $1.5 \mathrm{G}\left(100 \mathrm{~mW} \mathrm{~cm}^{-2}\right)$; and (b) IPCE spectra of the related devices.

\section{Photovoltaic properties}

To fully investigate the PV characteristics of (TPACN) $)_{2} \mathbf{Q x}$, the BHJ devices with a conventional structure of ITO/PEDOT:PSS/ $(\text { TPACN })_{2} \mathrm{Qx}: \mathrm{PC}_{61} \mathrm{BM} / \mathrm{Al}$ were fabricated by a solutionprocessed spin-coating technique. The optimization of (TPACN) $)_{2} \mathrm{Qx}$ and $\mathrm{PC}_{61} \mathrm{BM}(\mathrm{D} / \mathrm{A})$ weight ratios was studied in particular; herein, the blend of (TPACN) $)_{2} \mathbf{Q x}$ and $\mathbf{P C}_{61} \mathrm{BM}$ with varied weight ratios $(1: 1,1: 2$ and $1: 3)$ was performed. The $J-V$ curves of the devices with varied $\mathrm{D} / \mathrm{A}$ weight ratios are shown in Fig. 6(a), and the relevant PV parameters are listed in Table 2. The initial device was fabricated from the blend solution of (TPACN) $)_{2} \mathbf{Q x}$ and $\mathrm{PC}_{61} \mathrm{BM}$ in a $1: 1(\mathrm{w} / \mathrm{w})$ ratio, and it showed a PCE of $3.53 \%$ with $J_{\mathrm{SC}}$ of $8.23 \mathrm{~mA} \mathrm{~cm}{ }^{-2}, V_{\mathrm{OC}}$ of $0.94 \mathrm{~V}$ and FF of 0.46 . After the $\mathrm{D} / \mathrm{A}$ composition ratio was increased to $1: 2(\mathrm{w} / \mathrm{w})$, the PCE greatly increased to $6.25 \%$ with a high $J_{\mathrm{SC}}$ of $14.08 \mathrm{~mA}$ $\mathrm{cm}^{-2}, V_{\mathrm{OC}}$ of $0.95 \mathrm{~V}$ and $\mathrm{FF}$ of 0.47 . A 5.09\% drop in efficiency was observed on increasing the fullerene loading at the D/A composition ratio of $1: 3(\mathrm{w} / \mathrm{w})$, with a decreased $J_{\mathrm{SC}}$ of 12.86 $\mathrm{mA} \mathrm{cm}{ }^{-2}, V_{\mathrm{OC}}$ of $0.92 \mathrm{~V}$ and $\mathrm{FF}$ of 0.43 . Remarkably, the device based on (TPACN) $)_{2} \mathbf{Q x}: \mathrm{PC}_{61} \mathrm{BM}$ composition in a $1: 2$ weight

Table 1 The optical and electrochemical data of (TPACN) $)_{2} Q x$

\begin{tabular}{lllllll}
\hline Compound & $\lambda^{\mathrm{sol}}(\mathrm{nm}) / \varepsilon\left(\mathrm{M}^{-1} \mathrm{~cm}^{-1}\right)$ & $\lambda^{\mathrm{film}}(\mathrm{nm})$ & $E_{\mathrm{g}}^{\mathrm{opt}}(\mathrm{eV})$ & $E_{\mathrm{ox}}(\mathrm{V}) / \mathrm{HOMO}^{\mathrm{CV}}(\mathrm{eV})$ & $E_{\mathrm{red}}(\mathrm{V}) / \mathrm{LUMO}{ }^{\mathrm{CV}}(\mathrm{eV})$ & $E_{\mathrm{g}}^{\mathrm{CV}}(\mathrm{eV})$ \\
\hline${\text { (TPACN })_{2} \mathbf{Q x}}^{\text {Te }}$ & $433 / 108338,482 / 90762$ & 507 & $1.94(2.05)^{a}$ & $0.40 /-5.15$ & $-1.48 /-3.27$
\end{tabular}

${ }^{a}$ Data of the reference compound BDCTBT. ${ }^{10}$ 
Table 2 The hole mobility data and PV parameters of devices based on blend of (TPACN) $2 \mathrm{Qx}$ and $\mathrm{PC}_{61} \mathrm{BM}$ with varied D/A weight ratios

\begin{tabular}{|c|c|c|c|c|c|c|c|}
\hline $\begin{array}{l}(\mathrm{TPACN})_{2} \mathrm{Qx}: \mathrm{PC}_{61} \mathrm{BM} \\
(\mathrm{w} / \mathrm{w})\end{array}$ & $\mu_{\mathrm{h}}\left(\mathrm{cm}^{2} \mathrm{~V}^{-1} \mathrm{~s}^{-1}\right)$ & $R_{\mathrm{S}}\left(\Omega \mathrm{cm}^{2}\right)$ & $R_{\mathrm{sh}}\left(\mathrm{k} \Omega \mathrm{cm}^{2}\right)$ & $J_{\mathrm{SC}}\left(\mathrm{mA} \mathrm{cm}^{-2}\right)$ & $V_{\mathrm{OC}}(\mathrm{V})$ & $\mathrm{FF}$ & PCE $(\%)$ \\
\hline $1: 1$ & $5.19 \times 10^{-5}$ & 25 & 0.26 & 8.23 & 0.94 & 0.46 & 3.53 \\
\hline $1: 3$ & $8.66 \times 10^{-5}$ & 20 & 0.30 & 12.86 & 0.92 & 0.43 & 5.09 \\
\hline
\end{tabular}

ratio showed the optimal PV performance. This value is the highest efficiency reported so far for a solution-processed OSM PV-device using Qx as the electrophilic core. It should be noted that high efficiency might be closely related to a more optimized morphology of the active layer. The better PV performance of the device with $\mathrm{D} / \mathrm{A}$ ratio of $1: 2(\mathrm{w} / \mathrm{w})$ was further supported by atomic force microscopy (AFM) analysis of the blended (TPACN) ${ }_{2} \mathbf{Q x}: \mathrm{PC}_{61} \mathrm{BM}$ active layer (Fig. S14 in ESI $\dagger$ ). Although all the blend films with various $\mathrm{D} / \mathrm{A}$ composition ratios $(1: 1,1: 2$, $1: 3, \mathrm{w} / \mathrm{w}$ ) correspond to the favourable bicontinuous interpenetrating networks, the blend with a D/A ratio of $1: 2(\mathrm{w} / \mathrm{w})$ records the lowest surface roughness of $0.50 \mathrm{~nm}$ and the best interpenetrating network due to its smooth and homogeneous morphology, in agreement with its best PV performance. Moreover, the series resistance $\left(R_{\mathrm{S}}\right)$ of the device with $\mathrm{D} / \mathrm{A}$ ratio of $1: 2$ was reduced from $25 \Omega \mathrm{cm}^{-2}$ to $13 \Omega \mathrm{cm}^{-2}$, and the shunt resistance $\left(R_{\mathrm{sh}}\right)$ was increased from $0.26 \mathrm{~K} \Omega \mathrm{cm}^{-2}$ to $0.32 \mathrm{~K} \Omega$ $\mathrm{cm}^{-2}$, which contributes to the slightly improved FF and PCE values. The good performance of the (TPACN) $)_{2} \mathbf{Q x}$-based device demonstrates that Qx is a type of effective central-acceptor building block applied in OSM-PV materials.

Further experiment of PV characteristics was carried out with incident photon-to-current efficiency (IPCE) measurement, as shown in Fig. 6(b). All devices based on (TPACN) ${ }_{2}$ Qx with various $\mathrm{D} / \mathrm{A}$ composition ratios demonstrated significant photon-to-current responses in the range of 300-700 nm with the maximum IPCE of $96 \%, 79 \%$, and $58 \%$ at around $350 \mathrm{~nm}$, $91 \%, 79 \%$, and $62 \%$ at around $410 \mathrm{~nm}$ and $62 \%, 60 \%$, and $43 \%$ at around $500 \mathrm{~nm}$ for $\mathrm{D} / \mathrm{A}$ ratios of $1: 2,1: 3$ and $1: 1$, respectively, which were in accordance with the trend of their PCE values. In contrast, the device based on a D/A composition

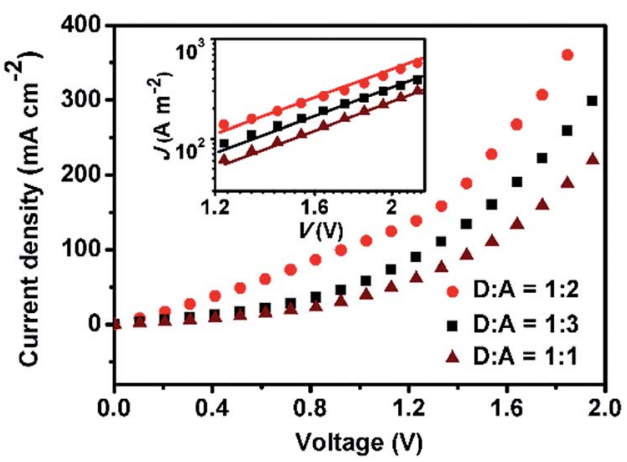

Fig. $7 \mathrm{~J}-V$ curves of the hole-only devices with different D/A composition ratios in dark. Inset: the $J-V$ curves at double logarithmic scale, and the solid lines are fitting plots of the data points by a SCLC model. ratio of $1: 2$ showed relatively high IPCE response, in line with its best PV performance.

To deeply understand the optoelectronic properties of (TPACN) $)_{2}$ Qx and have an insight into its PV performance, the holeonly devices were fabricated and measured to obtain the holemobility $\left(\mu_{\mathrm{h}}\right)$ with the space charge limitation of current (SCLC) method (the details are described in the Experimental section). ${ }^{18}$ The $\mu_{\mathrm{h}}$ is often regarded as one of the most important physical parameters for the design of PV donors, and it can be achieved in the dark with the structure of ITO/PEDOT:PSS/donor:PC ${ }_{61} \mathrm{BM} / \mathrm{Au}$. As a result, the $J-V$ characteristics of the devices at different weight ratios $(1: 1,1: 2$ and $1: 3)$ are depicted in Fig. 7 . Accordingly, the fitting plots of the data points in the SCLC regime are depicted in the inset of Fig. 7, and the $\mu_{\mathrm{h}}$ data can be derived in the region with a slope of 2 as shown in Table $2 .{ }^{25}$ The pertinent $\mu_{\mathrm{h}}$ values are $5.19 \times 10^{-5}, 1.29 \times 10^{-4}$ and $8.66 \times 10^{-5} \mathrm{~cm}^{2} \mathrm{~V}^{-1} \mathrm{~s}^{-1}$ for D/A ratios of $1: 1,1: 2$ and $1: 3$, respectively, which keeps a consistent trend with their $J_{\mathrm{SC}}$ and PCE values as expected. In contrast, the device based on a D/A ratio of $1: 2$ possesses the optimal hole transporting capacity, in agreement with the greatest $\mu_{\mathrm{h}}$ value among them. The results would probably give some valuable hints on the PV performance of devices and provide an important guide for developing new donor materials.

\section{Conclusions}

In summary, a novel $\mathrm{D}-\pi-\mathrm{A}-\pi-\mathrm{D}$-type OSM donor material, (TPACN) $)_{2}$ Qx, containing $\mathrm{Qx}$ as the electrophilic core, was designed and synthesized for solution-processable OSCs. The excellent PCE of $6.25 \%$ has been achieved based on an optimized D/A ratio of $1: 2$ using a simple spin-coating process from solution, which is the highest efficiency so far for solutionprocessed Qx-core based OSM BHJ-OSCs. The good PV performance is mainly attributed to the narrow $E_{\mathrm{g}}$, lower HOMO energy level and high $\mu_{\mathrm{h}}$ value caused by the effective electronwithdrawing property, relatively stable quinoid form of Qx and high hole-mobility capacity of (TPACN) $)_{2} \mathbf{Q x}$-based devices. The impressive result demonstrates that OSM donors employing a quinoxaline derivative as the electrophilic unit can compete with their polymer counterparts. This study clearly indicates that Qx-based OSMs possess great potential for obtaining high performance solution-processed PV devices. Further device optimization is underway in our laboratory.

\section{Acknowledgements}

This research was financially supported by the NSFC (No. 21102013, 21471024 and 21101020), the SRF from ROCS-SEM 
(No. 201001438 and 201001439) and the Fundamental Funds for the Central Universities (No. DUT16ZD205, DUT11LK20, DUT15ZD118 and DUT15LK20).

\section{Notes and references}

1 (a) P. Cheng and X. Zhan, Chem. Soc. Rev., 2016, 45, 25442582; (b) G. J. Hedley, A. Ruseckas and I. D. Samuel, Chem. Rev., 2017, 117, 796-837; (c) K. Leo, Nat. Rev. Mater., 2016, 1, 16056, DOI: 16010.11038/natrevmats.12016.16056.

2 (a) A. W. Hains, Z. Liang, M. A. Woodhouse and B. A. Gregg, Chem. Rev., 2010, 110, 6689-6735; (b) H. Kang, G. Kim, J. Kim, S. Kwon, H. Kim and K. Lee, Adv. Mater., 2016, 28, 7821-7861.

3 (a) J. C. Hummelen, B. W. Knight, F. LePeq and F. Wudl, J. Org. Chem., 1995, 60, 532-538; (b) M. M. Wienk, J. M. Kroon, W. J. Verhees, J. Knol, J. C. Hummelen, P. A. van Hal and R. A. Janssen, Angew. Chem., Int. Ed., 2003, 42, 3371-3375; (c) B. Kan, M. Li, Q. Zhang, F. Liu, X. Wan, Y. Wang, W. Ni, G. Long, X. Yang, H. Feng, Y. Zuo, M. Zhang, F. Huang, Y. Cao, T. P. Russell and Y. Chen, J. Am. Chem. Soc., 2015, 137, 3886-3893; (d) M. Li, K. Gao, X. Wan, Q. Zhang, B. Kan, R. Xia, F. Liu, X. Yang, H. Feng, W. Ni, Y. Wang, J. Peng, H. Zhang, Z. Liang, H.-L. Yip, X. Peng, Y. Cao and Y. Chen, Nat. Photonics, 2016, 11, 8590; (e) Y. Liu, L. A. Renna, M. Bag, Z. A. Page, P. Kim, J. Choi, T. Emrick, D. Venkataraman and T. P. Russell, ACS Appl. Mater. Interfaces, 2016, 8, 7070-7076.

4 (a) Y. Lin, Y. Li and X. Zhan, Chem. Soc. Rev., 2012, 41, 42454272; (b) O. Ostroverkhova, Chem. Rev., 2016, 116, 1327913412; (c) B. Walker, C. Kim and T.-Q. Nguyen, Chem. Mater., 2011, 23, 470-482.

5 D. Deng, Y. Zhang, J. Zhang, Z. Wang, L. Zhu, J. Fang, B. Xia, Z. Wang, K. Lu, W. Ma and Z. Wei, Nat. Commun., 2016, 7, 13740, DOI: 13710.11038/ncomms13740.

6 Y. Yang, Z. G. Zhang, H. Bin, S. Chen, L. Gao, L. Xue, C. Yang and Y. Li, J. Am. Chem. Soc., 2016, 138, 15011-15018.

7 Y. Li, Q. Guo, Z. Li, J. Pei and W. Tian, Energy Environ. Sci., 2010, 3, 1427-1436.

8 (a) H. Gao, Y. Li, L. Wang, C. Ji, Y. Wang, W. Tian, X. Yang and L. Yin, Chem. Commun., 2014, 50, 10251-10254; (b) C. Ji, L. Yin, K. Li, L. Wang, X. Jiang, Y. Sun and Y. Li, RSC $A d v .$, 2015, 5, 31606-31614; (c) L. Wang, L. Yin, C. Ji and Y. Li, Dyes Pigm., 2015, 118, 37-44.

9 (a) C. Ji, L. Yin, L. Wang, T. Jia, S. Meng, Y. Sun and Y. Li, J. Mater. Chem. C, 2014, 2, 4019-4026; (b) L. Wang, L. Yin, C. Ji, Y. Zhang, H. Gao and Y. Li, Org. Electron., 2014, 15, 11381148.

10 S. Zeng, L. Yin, C. Ji, X. Jiang, K. Li, Y. Li and Y. Wang, Chem. Commun., 2012, 48, 10627-10629.

11 S. Paek, N. Cho, K. Song, M.-J. Jun, J. K. Lee and J. Ko, J. Phys. Chem. C, 2012, 116, 23205-23213.

12 (a) D. W. Chang, S.-J. Ko, J. Y. Kim, L. Dai and J.-B. Baek, Synth. Met., 2012, 162, 1169-1176; (b) Y. Lee, Y. M. Nam and W. H. Jo, J. Mater. Chem., 2011, 21, 8583-8590; (c) H. J. Song, T. H. Lee, M. H. Han, J. Y. Lee and D. K. Moon, Polymer, 2013, 54, 1072-1079.
13 (a) M. L. Keshtov, S. A. Kuklin, N. A. Radychev, I. E. Ostapov, A. Y. Nikolaev, I. O. Konstantinov, M. M. Krayushkin, E. N. Koukaras, A. Sharma and G. D. Sharma, RSC Adv., 2016, 6, 71232-71244; (b) C. Lee, Y. Li, W. Lee, Y. Lee, J. Choi, T. Kim, C. Wang, E. D. Gomez, H. Y. Woo and B. J. Kim, Macromolecules, 2016, 49, 5051-5058; (c) Z. Lu, C.-h. Li, C. Du, X. Gong and Z.-s. Bo, Chin. J. Polym. Sci., 2013, 31, 901-911; (d) R. Singh, G. Pagona, V. G. Gregoriou, N. Tagmatarchis, D. Toliopoulos, Y. Han, Z. Fei, A. Katsouras, A. Avgeropoulos, T. D. Anthopoulos, M. Heeney, P. E. Keivanidis and C. L. Chochos, Polym. Chem., 2015, 6, 3098-3109; (e) E. Wang, L. Hou, Z. Wang, Z. Ma, S. Hellström, W. Zhuang, F. Zhang, O. Inganäs and M. R. Andersson, Macromolecules, 2011, 44, 2067-2073; (f) Y. Zhang, J. Zou, H.-L. Yip, K.-S. Chen, D. F. Zeigler, Y. Sun and A. K. Y. Jen, Chem. Mater., 2011, 23, 2289-2291.

14 (a) H.-C. Chen, Y.-H. Chen, C.-C. Liu, Y.-C. Chien, S.-W. Chou and P.-T. Chou, Chem. Mater., 2012, 24, 4766-4772; (b) D. Liu, W. Zhao, S. Zhang, L. Ye, Z. Zheng, Y. Cui, Y. Chen and J. Hou, Macromolecules, 2015, 48, 5172-5178; (c) J. Yuan, L. Qiu, Z. Zhang, Y. Li, Y. He, L. Jiang and Y. Zou, Chem. Commun., 2016, 52, 6881-6884.

15 (a) X. Li, Y. Zhou, J. Chen, J. Yang, Z. Zheng, W. Wu, J. Hua and H. Tian, Chem. Commun., 2015, 51, 10349-10352; (b) K. Pei, Y. Wu, A. Islam, S. Zhu, L. Han, Z. Geng and W. Zhu, J. Phys. Chem. C, 2014, 118, 16552-16561; (c) K. Pei, Y. Wu, H. Li, Z. Geng, H. Tian and W. H. Zhu, ACS Appl. Mater. Interfaces, 2015, 7, 5296-5304; (d) J. Yang, P. Ganesan, J. Teuscher, T. Moehl, Y. J. Kim, C. Yi, P. Comte, K. Pei, T. W. Holcombe, M. K. Nazeeruddin, J. Hua, S. M. Zakeeruddin, H. Tian and M. Grätzel, J. Am. Chem. Soc., 2014, 136, 5722-5730.

16 (a) D. Kekuda, J.-S. Huang, M. Velusamy, J. T. Lin and C.-W. Chu, Sol. Energy Mater. Sol. Cells, 2010, 94, 17671771; (b) W. Li, D. Wang, S. Wang, W. Ma, S. Hedström, D. I. James, X. Xu, P. Persson, S. Fabiano, M. Berggren, O. Inganäs, F. Huang and E. Wang, ACS Appl. Mater. Interfaces, 2015, 7, 27106-27114; (c) J. A. Mikroyannidis, A. N. Kabanakis, A. Kumar, S. S. Sharma, Y. K. Vijay and G. D. Sharma, Langmuir, 2010, 26, 12909-12916.

17 (a) Z. Li, Y. Zhang, A. L. Holt, B. P. Kolasa, J. G. Wehner, A. Hampp, G. C. Bazan, T.-Q. Nguyen and D. E. Morse, New J. Chem., 2011, 35, 1327-1334; (b) C.-Y. Yu, C.-P. Chen, S.-H. Chan, G.-W. Hwang and C. Ting, Chem. Mater., 2009, 21, 3262-3269.

18 (a) P. W. M. Blom, M. J. M. de Jong and M. G. van Munster, Phys. Rev. B: Condens. Matter, 1997, 55, R656-R659; (b) Z. Li, Q. Dong, Y. Li, B. Xu, M. Deng, J. Pei, J. Zhang, F. Chen, S. Wen, Y. Gao and W. Tian, J. Mater. Chem., 2011, 21, 2159-2168.

19 Q. Peng, J. Xu and W. Zheng, J. Polym. Sci., Part A: Polym. Chem., 2009, 47, 3399-3408.

20 (a) Y. Chen, C. Li, P. Zhang, Y. Li, X. Yang, L. Chen and Y. Tu, Org. Electron., 2013, 14, 1424-1434; (b) F. Liang, J. Lu, J. Ding, R. Movileanu and Y. Tao, Macromolecules, 2009, 42, 61076114. 
21 Y. Cui, P. Li, C. Song and H. Zhang, J. Phys. Chem. C, 2016, 120, 28939-28950.

22 R. Chen, Y. Wang, T. Chen, H. Li, C. Zheng, K. Yuan, Z. Wang, Y. Tao, C. Zheng and W. Huang, J. Phys. Chem. B, 2015, 119, 583-591.
23 S. So, H. Choi, C. Kim, N. Cho, H. M. Ko, J. K. Lee and J. Ko, Sol. Energy Mater. Sol. Cells, 2011, 95, 3433-3441.

24 Q. Liu, Y. Liu, Y. Wang, L. Ai, X. Ouyang, L. Han and Z. Ge, New J. Chem., 2013, 37, 3627-3633.

25 L. Wang, L. Yin, L. Wang, B. Xie, C. Ji and Y. Li, Dyes Pigm., 2017, 140, 203-211. 